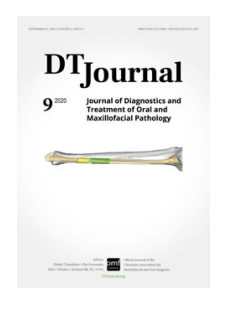

EDITORIAL

\section{Introducing the Editorial Board Member from Philadelphia, Pennsylvania: Andrew Yampolsky, DDS, MD}

\author{
Oleksii O. Tymofieieva, levgen I. Fesenko ${ }^{b}$, \& \\ Anastasiya Quimby
}

Nice to see OMS flourishing in my motherland. -Dr. Yampolsky (personal communication, 2019)

Uniting the best microvascular surgeons in the Editorial Board became a new honorary tradition of our journal. We are enormously proud to receive the acceptance and wise support of Dr. Yampolsky (Fig 1).

Andrew Yampolsky, DDS, MD is a Director, Maxillofacial Surgical Oncology and Microvascular Reconstruction, Department of Oral and Maxillofacial Surgery in Thomas Jefferson University Hospital, Philadelphia, Pennsylvania.

Dr. Yampolsky's numerous cutting-edge works continue to inspire our team to expand the portfolio of articles focused on jaw reconstructive techniques. ${ }^{1-5}$ One of the masterpieces we are really enjoying is a "Fibula Condyle in a Day" technique. ${ }^{5}$ Report perfectly describes experience in creating fibula free flap neo-

\footnotetext{
DTJournal.org

a Editor in Chief, Kyiv, Ukraine.

E-mail: tymofeev@gmail.com (Oleksii Tymofieiev)

${ }^{\mathrm{b}}$ Managing Editor, Kyiv, Ukraine.

E-mail: i.i.fesenko@dtjournal.org (levgen Fesenko)

Instagram: @dr_eugenfesenko

${ }^{\circ}$ Editorial Board Member, Fort Lauderdale, Florida, United States

E-mail: aquimby@nova.edu (Anastaysia Quimby)

Instagram: @anastasia_q.
}

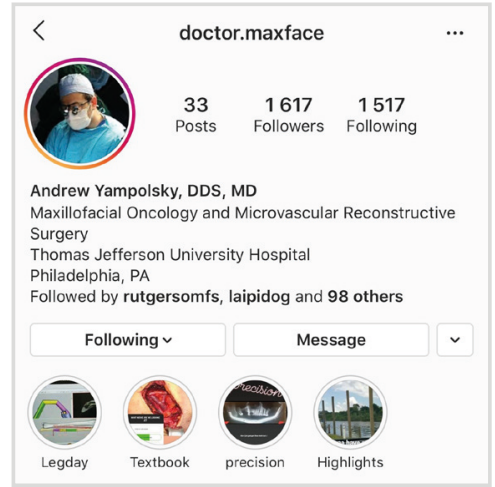

FIGURE 1. Instagram page of Dr. Yampolsky (@doctor.maxface).

condyle with soleus muscle used as an intermediate layer to fill in the defect between new condyle and the skull base.

So, dear Dr. Yampolsky, thank you for moving the surgery forward and thank you for joining the multinational team of the dtjournal.org!

\section{REFERENCES}

1. Yampolsky A, Aziz S. Horizontal alveolar distraction osteogenesis: complications and their management. In: Tolstunov L, editor. Horizontal alveolar ridge augmentation in implant dentistry: a surgical manual. 1st ed. Hoboken, New Jersey: Wiley; 2016:259-60.

2. Shanti RM, Yamposky A, Milles $M$, Braidy $H$. Ultrasonic welded resorbable mesh (SonicWeld $\mathrm{Rx}$ System) in reconstruction of segmental mandibular defects: technical note and report of 2 cases. J Oral Maxillofac Surg 2015;73(11):2241-50.

3. YampolskyA,ZiccardiV,ChuangSK.Efficacyofacellular nerve allografts in trigeminal nerve reconstruction. $J$ Oral Maxillofac Surg 2017;75(10):2230-4.

4. Taub D, Yampolsky A, Diecidue R, Gold L. Controversies in the management of oral and maxillofacial infections. Oral Maxillofac Surg Clin North Am 2017;29(4):465-73.

5. Zaid WY, Alshehry S, Zakhary G, Yampolsky A, Kim B. Use of vascularized myo-osseous fibula free flap to reconstruct a hemimandibular defect with a concomitant skull defect arising from stock condylar prosthesis displacement into the middle cranial fossa. $J$ Oral Maxillofac Surg 2019;77(6):1316.e1-1316.e12.

\footnotetext{
Please cite this article as: Tymofieiev OO, Fesenko II, Quimby A. Introducing the editorial board member from Philadelphia, Pennsylvania: Andrew Yampolsky, DDS, MD. J Diagn Treat Oral Maxillofac Pathol 2020;4(9):151.

Paper received 16 September 2020

Accepted 23 September 2020

Available online 30 September 2020

https://dx.doi.org/10.23999/j.dtomp.2020.9.1

(c) 2020 OMF Publishing, LLC. This is an open access article under the CC BY license (http://creativecommons.org/licenses/by-nc/4.0/).
} 